\title{
Üçüncü basamak bir hastanede çocukların büyümelerine etkili faktörlerinin retrospektif değerlendirilmesi
}

\section{Retrospective evaluation of determinants of young children growth status in a tertiary care hospital}

\author{
Ayşe KAMAN ${ }^{1 *}$ Emine POLAT2 2 , Can Demir Karaca $n^{3}$
}

'Dr Sami Ulus Kadın Doğum Çocuk Sağlığı Ve Hastalıkları Eğitim Araştırma Hastanesi, Çocuk Enfeksiyon Kliniği,Ankara

${ }^{2}$ Dr Sami Ulus Kadın Doğum Çocuk Sağlığı Ve Hastalıkları Eğitim Araştırma Hastanesi, Çocuk Kliniği, Ankara

${ }^{3}$ Dr Sami Ulus Kadın Doğum Çocuk Sağlığı Ve Hastalıkları Eğitim Araştırma Hastanesi, Çocuk Acil Kliniği, Ankara

\section{Öz}

Amaç: Büyüme ve gelişmenin en hızlı olduğu 0-5 yaş arası dönem, sağlıklı gelişimi olumsuz etkileyen çok sayıda etmene karşı oldukça duyarlı bir dönemdir. Bu çalışmada 5 yaş altındaki hastaların beslenme öyküleri, büyüme parametrelerini belirlemek ve bu parametreleri etkileyebilecek faktörlerin tespiti amaçlandı.

Gereç ve Yöntemler: Çalışmaya Aralık 2011-Mayıs 2012 ayları arasında yatırılarak tedavi edilen 5 yaş altındaki çocuklar dahil edildi.

Bulgular: Çalışmaya ortanca yaşları 8 ay (1-59 ay) olan 344 hasta (\%54,7erkek) dahil edildi. Doğum sonrası hastaların \%97,1'i anne sütü ile beslenmeye başlanmışken, çalışma sırasında bir yaştan büyük olanların \%18'i 1 yıldan kısa süre emzirilmişti. Hastaların 6. ayda tek başına anne sütü ile beslenme oranı \%30,8'di. Hastaların annelerinin eğitim durumu ve ailelerin aylık gelir düzeyleri Türkiye ortalamasından düşük bulundu. Anne-baba yaşı, ebeveyn eğitim düzeyi ve ailenin aylık geliri ile kilo ve boy persantilleri arasında ilişki saptanmadı. Anne yaşı ve annenin eğitim düzeyi ile tek başına anne sütü ile beslenme süresi arasında ilişki bulunmazken, ailenin aylık geliri arttıkça tek başına anne sütü alım süresini uzadığı tespit edildi ( $p<0.05)$. Anne yaşı, annenin eğitim düzeyi ve ailenin aylık geliri ile toplam anne sütü ile beslenme süresi arasında ilişki saptanmadı. Hastaların tek başına anne sütü alımı süreleri arttıkça kilo ve boy persantillerinin istatistiksel olarak arttığı tespit edilirken $(p<0.05)$ toplam anne sütü alım süresi ile kilo ve boy persantil değerleri arasında ilişki bulunmadı.

Sonuç: Ülkemizde erkek ve kadın arasındaki eğitime katılım farklıı̆ı halen devam etmektedir. Ailenin aylık geliri tek başına anne sütü ile beslenme süresi üzerine etkilidir. Anne sütü alım süresi büyüme parametreleri üzerine en etkili faktördür.

Anahtar kelimeler: Büyüme; emzirme; süt çocuğu; yetersiz beslenme

Sorumlu Yazar*: Ayşe Kaman Doktor Sami Ulus Kadın Doğum Çocuk Sağlığı Ve Hastalıkları Eğitim Araştırma Hastanesi, Çocuk Enfeksiyon Kliniği, Ankara/TÜRKiYE

E-mail: ayse092003@yahoo.com

ORCID: 0000-0002-6188-6816

Gönderim: 30.05.2019 Kabul: 08.01.2020

Doi: $10.18663 /$ tjcl.571889 


\begin{abstract}
Aim: During the first five years of life, children are highly sensitive against factors that adversely affect development. The aim of this study was to determine the nutritional history and growth parameters of patients under 5 years of age and the factors that might affect these parameters.
\end{abstract}

Material and Methods: The study included children under 5 years of age at a tertiary care pediatric hospital between December 2011 and May 2012.

Results: Three-hundred and forty-four patients (54.7\% male) with median age of 8 months (1-59 months) were included in study. While $97.1 \%$ of the mothers were initiated breastfed after the delivery, $18 \%$ of those older than 1 years were breastfed for less than 1 year. The rate of exclusively breastfeeding at the 6 months of age was 30.8\%. Educational status of mothers and monthly family income were lower than the average in Turkey. There was no correlation between age of parents, parental education level, family income and weight and height percentile. There was no correlation between age and educational level of mother and the duration of breastfeeding, but the duration of exclusive breastfeeding was positive correlated with the monthly family income $(p<0.05)$. It was found that wieght and hight percentages were positive correlated with exclusive breastfeeding duration $(p<0.05)$, but there was no correlation with total breastfeeding duration.

Conclusion:In our country, there is still a difference in participation in education between men and women. The monthly income of the family is effective on breastfeeding alone. Exclusively breastfeeding duration is the most effective factor on growth parametres.

Keywords: Growth; breastfeeding; infant; undernutrition

\section{Giriş}

Çocukların sağlık durumlarının değerlendirilmesinde en iyi gösterge büyümedir. Büyüme, genetik faktörlerin yanı sıra çevresel faktörlerden etkilenir. Yetersiz gıda alımı ve sık geçirilen enfeksiyonlar, gelişmekte olan birçok ülkede büyüme geriliğinin en önemli iki nedenidir. Çocuklarda normal büyüme ve gelişmenin bilinmesi, normal durumlardan sapmaların tanımlanması yoluyla hastalıkların belirlenmesi ve önlenmesi açısından gereklidir. Büyüme ve gelişmenin en hızlı olduğu 0-5 yaş arası dönem, sağlıklı gelişimi olumsuz etkileyen çok sayıda etmene karşı oldukça duyarlı bir dönemdir. Temel sağlık hizmetlerinin önemli bir bölümünü çocukların büyüme ve gelişmelerinin izlemi oluşturmaktadır [1]. Hastaların izleminin eksiksiz yapılabilmesi için sağlık kuruluşlarında hastaların boy, kilo ölçümlerinin ve kayıtlarının eksiksiz olması önemli bir konudur. Bu çalışmada 5 yaş altındaki hastaların beslenme öyküleri ve büyüme parametrelerinin belirlenmesi ve bu parametreleri etkileyebilecek faktörlerin tespit edilmesi amaçlandı.

\section{Gereç ve Yöntemler}

Çalışmaya Aralık 2011- Mayıs 2012 ayları arasında hastanemizde yatırılarak takip ve tedavi edilen, 5 yaş altındaki 344 hasta dahil edildi. Hastaların dosya verilerinden yaş, cinsiyet, yaşadıkları şehir, tanı sırasındaki boy ve vücut ağılıkları, yatış tanıları, eşlik eden kronik hastalık, hastanede yatış öyküsü, aşılanma durumu, anne ve baba yaşları, ebeveynler arasında akrabalık durumu, ebeveynlerin eğitim durumu ve ortalama aylıkgelirleri, ev içi sigara teması ile anne sütü alım süreleri ve ek gıdaya geçiş zamanları ile ilgili verileri geriye dönük olarak kaydedildi. Hastaların büyüme durumlarını belirlemek için kullanılan yaşa göre ağırlık ve yaşa göre boy persantil değerleri Neyzi ve arkadaşlarının 2008 yılı eğrileri kullanılarak hesaplandı [2]. Preterm doğum öyküsü olan hastaların persantilleri hesaplanırken düzeltilmiş yaşları esas alındı. İkili karşılaştırmalarda boy ve kilo persantil ölçümleri alınırken, $\leq 25$ persantil, 25-50 persantil arası, 50-75 persantil, ve $\geq 75$ persantil değerlerine göre hastalar sınıflandı. Çalışma Helsinki İlkeler Deklerasyonuna uyularak gerçekleştirilmiştir.

İstatistiksel analizler analizleri Statistical Package for the Social Sciences (SPSS) for Windows Version 16.0 paket programında yapıldı. Sayısal değişkenler ortalama \pm standart sapma veya median [min- maks] değerler ile özetlendi. Nitelik değişkenler ise sayı ve yüzde ile gösterildi. Sayısal değişkenlerin normalliği Kolmogorov Smirnov testi ile incelendi. Gruplar arasında nitelik değişkenler bakımından farklııı olup olmadığı ki kare testi ile araştırıldı. Sayısal değişkenler bakımından gruplar arasında farklılık olup olmadığı ise; Kruskal Wallis testi ile incelendi. Anlamlılık düzeyi $\mathrm{p}<0,05$ olarak alındı.

\section{Bulgular}

Çalışmaya hastanemiz yataklı servislerinde izlenen, 5 yaş altındaki 344 hasta dahil edildi. Hastaların 188'i (\%54,7) erkek, 156 'sı $(\% 45,3)$ kızdı. Hastalarda ortanca yaş 8 ay (1-59 ay), ortalama yaş 15,5 \pm 16 ay olarak tespit edildi. En sık hastaneye yatış tanıları sırasıyla akut alt solunum yolu enfeksiyonu (\%47), yumuşak doku enfeksiyonu ve lenfadenit $(\% 13,3)$ ile ateş etyolojisi $(\% 8,1)$ idi.

Gebelik haftasına göre hastaların \%11'i <37 hafta, \%86,3'ü 37-42 hafta, \%2,7'si $\geq 42$ hafta idi. Yedi hastanın evde doğum öyküsü mevcuttu. Hastaların \%53,4'ü normal spontan vajinal yolla 
doğmuştu ve \%23,4'ünün anne ve babaları arasında akrabalık mevcuttu. Hastaların yaşayan kardeş sayısı ortancası 1 (0-7) ve ortalaması 1,17 $\pm 1,13$ idi. On sekiz hastanın kardeş ölümü öyküsü vardı. Çalışma döneminde yürürlükte olan aşı programına göre, hastaların \%96,2'si yaşına göre eksiksiz olarak aşılanmıştı. On iki hastanın yaşına göre eksik aşıları var iken, bir hastanın hiç aşısı yapılmamıştı. Hastaların anne ve baba yaş dağııımları ile hastaların ebeveynlerinin eğitim seviyeleri ve ev içi aylık ortalama gelirleri Tablo 1'de

\begin{tabular}{|c|c|c|}
\hline Çalışma değişkeni & Veri & $n(\%)$ \\
\hline \multicolumn{3}{|l|}{ Anne Yaşı } \\
\hline$<18$ yaş & 7 & 2,1 \\
\hline $18-25$ yaş & 102 & 30,4 \\
\hline $25-35$ yaş & 188 & 56,1 \\
\hline$\geq 35$ yaş & 38 & 11,3 \\
\hline \multicolumn{3}{|l|}{ Baba Yaşı } \\
\hline$<18$ yaş & 1 & 0,3 \\
\hline $18-25$ yaş & 33 & 10 \\
\hline $25-35$ yaş & 206 & 62,2 \\
\hline$\geq 35$ yaş & 91 & 27,5 \\
\hline \multicolumn{3}{|l|}{ Anne Eğitim Düzeyi } \\
\hline Okuma yazma bilmiyor & 13 & 5,9 \\
\hline Illköğretim mezunu & 67 & 74 \\
\hline Lise mezunu & 18 & 14,2 \\
\hline Yüksek öğretim mezunu & 13 & 5,9 \\
\hline \multicolumn{3}{|l|}{ Baba Eğitim Düzeyi } \\
\hline Okuma yazma bilmiyor & 4 & 1,8 \\
\hline İlköğretim mezunu & 132 & 60,3 \\
\hline Lise mezunu & 64 & 29,2 \\
\hline Yüksek öğretim mezunu & 19 & 8,7 \\
\hline \multicolumn{3}{|l|}{ Aylık Ortalama Gelir } \\
\hline$<1000 \mathrm{TL}$ & 74 & 33,3 \\
\hline $1000-1500 \mathrm{TL}$ & 98 & 44,1 \\
\hline $1500-2000 \mathrm{TL}$ & 29 & 13,1 \\
\hline$>2000 \mathrm{TL}$ & 21 & 9,5 \\
\hline
\end{tabular}

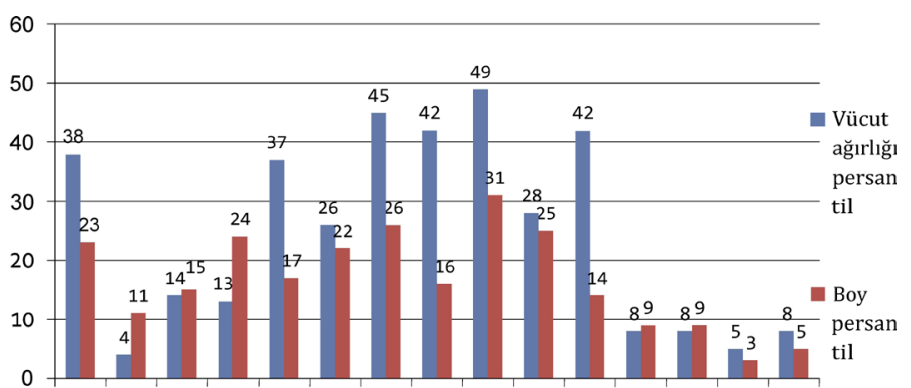

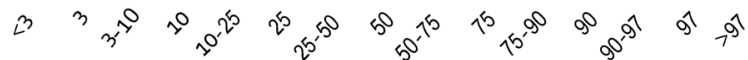

vücut ağırlığı ve boy persantillerine göre dağılımı Şekil 1'de gösterildi.

Annenin yaşı ve eğitim düzeyi, babanın yaşı ve eğitim düzeyi ile kilo ve boy persantilleri arasında da anlamlı bir ilişki bulunamadı. Ayrıca ailenin aylık ortalama geliri ile hastaların kilo ve boy persantilleri arasında istatistiksel olarak anlamlı bir fark saptanmadı ( $p>0.05$ ). Yaşayan kardeş sayısı ile kilo ve boy persantil değerleri arasında istatistiksel olarak anlamlı bir ilişki yoktu ( $p>0.05$ ).Çalışmaya dahil edilen hastaların \%70'inin ev içinde sigara maruziyeti ile ilgili verileri mevcuttu ve bu hastaların \%45,7'sinin en az bir kişi nedeniyle ev içi sigara maruziyeti vardı. Hastaların kilo ve boy persantil değerleri ile ev içi sigara maruziyeti arasında anlamlı bir ilişki saptanmadı ( $>0.05)$. Hastaların \%3,8'inin eşlik eden kronik hastalığı mevcutken, \%38,1'inin daha önce çeşitli nedenlerle hastanede yatış öyküsü mevcuttu. Hastaların boy persantilleri ile hastaneye yatış öyküsü arasından anlamlı ilişki saptanmazken $(p>0.05)$ daha önce hastaneye yatış öyküsü olanlarda vücut ağırlığı persantillerinin yatış öyküsü olmayanlara göre anlamlı olarak düşük olduğu saptandı $(p<0,05)$.

Hastaların \%88'inin anne sütü ile beslenme ile ilgili verilerine, $\% 66,9$ 'unun D vitamin profilaksisi kullanım süresi ve $\% 43,3$ 'ünün demir profilaksisi kullanım süresi ile ilgili verilerine ulaşılmıştı (Tablo 2). Doğum sonrası hastaların $\% 97,1$ 'i anne sütü ile beslenmeye başlanmıştı ve çalışma sırasında 1 yaştan büyük olan çocukların yalnız \%18'i 1 yaşından kısa süre emzirilmişti. Ancak çalışma sırasında 6 aylıktan büyük olan hastalarda, 6 . ayda tek başına anne sütü ile beslenme oranı \%30,8'di. Anne yaşı ve annenin eğitim düzeyi ile tek başına anne sütü ile beslenme süresi arasında ilişki bulunmazken $(p>0.05)$, ailenin aylık geliri arttıkça tek başına anne sütü alım süresini uzadığı tespit edildi $(p<0.05)$. Anne yaşı, annenin eğitim düzeyi ve ailenin aylık geliri ile toplam anne sütü ile beslenme süresi arasında ilişki saptanmadı ( $p>0.05)$. Hastaların tek başına anne sütü alımı süreleri arttıkça kilo ve boy persantillerinin istatistiksel olarak arttığı tespit edilirken $(p<0.05)$ toplam anne sütü alım süresi ile kilo ve boy persantil değerleri arasında ilişki bulunmadı ( $p>0.05$ ). Ek gıdaya başlama yaşı ile kilo ve boy persantil değerleri arasında istatistiksel olarak anlamlı bir sonuç bulunamadı ( $p>0.05$ ). Anne eğitim düzeyi arttıkça bebeklerin $D$ vitamini kullanım süresinin daha uzun olduğu tespit edildi $(p<0.001)$.

Şekil 1. Hastaların kilo ve boy persantillerinin dağılımı 


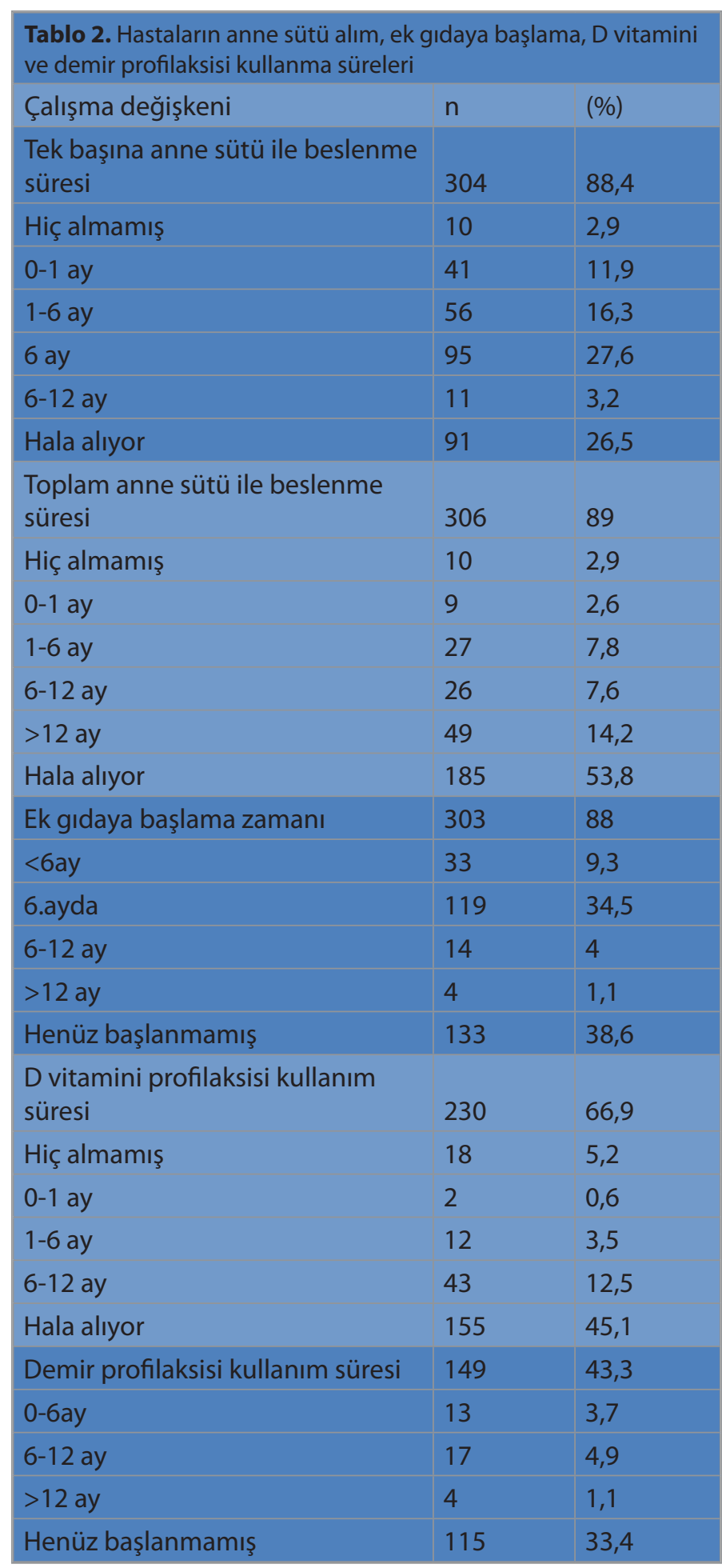

\section{Tartışma}

Çocukluk çağında ayaktan tedavi edilen hastaların yaklaşık olarak dörtte biri ve hastaneye yatırılan hastaların ilk yaşta \%33-50'sinin, tüm yaş gruplarında \%29-38'inin pnömoni tanısı aldığı tespit edilmiştir [3]. Portekiz'de, 5 yaşından küçük 722 hastanın dahil edildiği bir çalışmada, hastaların \%42'si 1 yaşından küçük, erkek/ kız oranı 1.8 ve en sık yatış tanısı solunum yolu enfeksiyonları olarak tespit edilmiştir [4]. Ülkemizde 5 yaş altındaki 3320 hastanın dahil edildiği çalışmada ise erkek/kız oranı 1,63 ve en sık yatış tanısı ishalli hastalıklar olarak bulunmuştur. Bu farklılık çalışma bölgesinde mevsimsel olarak ishalli hastalıkların yaz aylarında, alt solunum yolu enfeksiyonlarının ise kış aylarında hastaneye yatışın en sık nedeni olması ile açıklanabilmektedir [5]. Beş yaş altında, hastanede yatırılarak izlenen hastaları içeren çalışmamızda da en sık yatış tanısı alt solunum yolu enfeksiyonları idi ve hastaların çoğunluğu 1 yaşından küçüktü.

Herhangi bir enfeksiyon sırasında iken normal öğün sayısından az yemek yiyen çocukların sayısının daha fazla olduğu, ancak hastalık sırasındaki yeme alışkanlığının nütrisyonel durum ile ilişkisinin olmadığı bulunmuştur [6]. Ayrıca enfeksiyon sırasında immün sistem, patojenle savaşmak için geniş bir besinsel gereksinimi kullanır ve enfeksiyonlar çocuk büyümesi üzerine beslenmenin olumlu etkisinin azalması ile sonuçlanabilir [7]. Kliniğimizde 2006-2011 yılları arasında 5 yaş altındaki malnütrisyon tanısı alan hastalarda yapılan çalışmada ise daha önce hastanede yatış oranı \%54 bulunmuş ve bu hasta grubunun yatışları sırasında hem akut hem de kronik malnütrisyonun göstergesi olan yaşa göre ağırlık z-skorlarının daha önce hiç hastanede yatmamış hastalarınkine göre anlamlı olarak düşük olduğu saptanmıştır [8]. Bizim çalışmamızda da benzer olarak hastaların yaklaşık üçte biri daha önce çeşitli nedenlerle hastanede yatırılmıştı ve bu hastaların kilo persantilleri anlamlı olarak düşük bulunmuştu.

Ülkemizde TNSA 2008 verilerine göre sağlık kuruluşunda doğum oranları $\% 90$, prematüre doğum oranı $\% 10$ olarak bildirilmiştir [9]. TNSA-2013 araştırması sonuçlarına göre ise sağlık kuruluşunda doğum oranı \%97'dir [10]. Ayrıca yürütülen genişletilmiş bağışıklama programı sonucunda 1993 yılında \%77 olan aşılanma oranının yıllar içinde artığı bildirlmiştir (11). Ocak 2005 ve sonrasında doğan çocuklar için aşı takvimine göre eksiksiz aşılanma oranı \% 81 , hiç aşılanmamış çocuk oranı ise \%2 olarak rapor edilmiştir [9]. Türkiye İstatistik Kurumu 2011 verilerine göre ise akraba evliliği oranı \% 21,2 ve akraba evliliği yapanların, birinci derece akraba evliliği oranı \% 51,9 olarak tespit edilmiştir [12]. Bizim çalışmamızda sağlık kuruluşunda doğum ve aşılanma oranları çalışmanın yapıldığı dönemde bildirilen Türkiye ortalamasından yüksek saptanmış olup, akraba evliliği, prematüre doğum oranları ülkemiz verileri ile benzer bulunmuştur. Bu durum hastaların çoğunluğunun Ankara ilinden başvurması ve bu bölgede sağılı hizmetlerine erişilebilirliğin yüksek olması ile açıklanabilir.

Ülkemiz TNSA-2008 verilerine göre erkeklerin \%25,9'u kadınların \%18,2'si lise ve üzeri eğitime sahiptir [9]. 2013 yılında yapılan TNSA'na göre ise hem erkek hem de kadın cinsiyette lise ve üzeri eğitime sahip olanların oranı artarken eğitimi olmayan ya da ilkokulu bitirmemiş bireylerin oranı düşmüştür $[9,10]$. Türkiye Aile Yapısı Araştırması 2011 verilerine göre Türkiye'deki 
ailelerin \%38,5'inin aylık ortalama geliri asgari ücret sınırının altında iken \%21,5'inin aylık geliri asgari ücretin 2 katı kadardır [13]. Bizim çalışmamızda babaların eğitim düzeyleri ülkemiz verilerinden daha yüksek ancak annelerin eğitim düzeyleri ülkemiz verilerinden daha düşüktü. Ebeveynler arasında erkek ve kadın arasındaki eğitime katılım farklılıklarının halen devam ettiği görülmektedir. Bu çalışmada asgari ücret alan ailelerin oranı ülkemiz verileri ile benzerken, daha üst gelir seviyesinde olanların yüzdesi daha düşüktür. Bunun sebebi hastanemizin bulunduğu bölgenin gelir düzeyinin düşük olması olabilir.

Literatürde çocukların büyüme parametreleri üzerinde hem annenin hem de babanın eğitim seviyesinin etkili olduğunu gösteren çalışmalar mevcuttur [14, 15]. Brezilya'da yapılan kesitsel bir çalışmada çocukların büyüme parametreleri üzerine annenin eğitim düzeyi, kişi başına düşen aylık gelir ve evde yaşayan kişi sayısının etkili olduğu bulunmuştur [16]. Hindistan'da okul öncesi çocukların büyüme ve beslenme durumlarının sorgulandığı bir çalışmada ise annenin eğitim durumunun çocuk beslenmesini etkileyen tek değişken olduğu tespit edilmiştir [17]. Bu çalışmaların aksine çocukların büyümesi üzerine etkili sosyoekonomik faktörleri değerlendiren bir çalışmada çocukların büyüme parametreleri ile babalarının eğitim düzeyi arasında anlamlı ilişki bulunmuş; ancak anne eğitim düzeyinin, çocukların nütrisyonel durumuna pozitif etkisinin olmadığı ve yaşa göre boy ve kilo değerlerini etkilemediği bulunmuştur [18]. Ülkemizde yapılan bir anket çalışmasında ise kilo ve boy persantillerinin cinsiyet, annenin eğitimi ve sigara kullanımı durumuna göre farklılık göstermediği tespit edilmiştir [19]. Nepal'de annenin doğumdaki yaşı, doğum aralığı, babanın eğitim düzeyi, ailenin sosyoekonomik durumu, biberonla beslenme, emzirmeye başlama zamanı, tek başına anne sütü ile beslenme süresi ve ek gıdaya başlama zamanının 5 yaşın altındaki çocuklarda akut malnutrisyonun belirleyicileri olduğu bildirilmiştir [20]. Anne yaşı ve evdeki çoçuk sayısının, hastaların yaşa göre boy z skorları ile negatif yönde ilişkili olduğunu bildiren yayınlar mevcutdur [21]. Bizim çalışmamızda ise anne ve baba eğitim düzeyleri ve ailenin ortalama aylık geliri ile hastaların kilo ve boy persantilleri arasında ilişki saptanmadı.

Amerika Birleşik Devletleri'nde ırklar arasında belirgin farklılıklar bulunmakla birlikte emzirmeye başlama oranı \%75 olarak tespit edilmiştir. Siyah ırkta emzirmeye başlama oranı \%58,1 iken Latin Amerikalılarda bu oran \%80,6'ydı. Benzer şekilde gelir düzeyi ve annenin yaşı ile de emzirme süreleri arasında farklılık tespit edilmiştir. Buna göre 20 yaşından küçük annelerde emzirmeye başlama oranı \%59,7 iken, 30 yaşın üzerindeki annelerde bu oran \%79,3 olarak bulunmuştur [22]. Bangladeş'te doğumdan sonra anne sütüne başlama oranı $\% 27,5$, altı ayın altında tek başına anne sütü ile beslenme ise
\%42,5 olarak saptanmıştır. Tek başına anne sütü alma oranları sosyoekonomik durumu ve anne eğitim düzeyi yüksek olanlarda daha düşük bulunmuştur [23]. Ülkemiz verilerine göre doğumdan sonra annelerin yaklaşık \%97'sinin emzirmeye başladığı bilinmektedir. Yaşamlarının ilk iki ayında bebeklerin \%58'inin sadece anne sütü ile beslendiği ve sadece anne sütü ile beslenme oranının yıllar içinde azaldığı gösterilmiştir. Erkek ve kız bebeklerin ortanca emzirme süreleri farklı olmakla birlikte tüm çocuklar için ortalama emzirilme süresi 16,7 aydır. Hiç emzirilmemiş bebek sayısı az olmasına rağmen, yaşamın ilk aylarında çok yoğun biçimde hazır mama kullanıldığı, ilerleyen yaşla birlikte diğer süt çeşitlerinin de verildiği rapor edilmiştir. Türkiye'de emzirmeye başlama yaygın olmasına karşın tek başına anne sütü ile beslenme alışkanlığı arzu edilen seviyede değildir [9, 10]. Ülkemizde yapılan bir çalışmada ortalama anne sütü alımı süresi 9,31 \$5,66 ay, ortalama tek başına anne sütü alım süresi ise $4,67 \pm 1,91$ olarak tespit edilmiş ve kilo persantilleri ile anne sütü alma süreleri arasında istatistiksel olarak anlamlı farklılık görülmüştür. Bununla birlikte kilo persantilleri ile, tek başına anne sütü alma, formula alma, tamamlayıcı gıdalara geçiş süreleri arasında anlamlı farklılık bulunmamıştır [19]. Ülkemizde emzirmeye başlama ve devam oranı endüstrileşmiş toplumlardan daha yüksek bulunmuştur. Bizim çalışmamızda da emzirmeye başlama oranları Türkiye verileri ile benzerken emzirmeye devam yüzdesi daha düşük görünmektedir. TNSA-2008 verilerine göre ise ülkemizde erkek çocuklar, kırsal kesimde ve Orta Anadolu bölgesinde yaşayan çocuklar, ilköğretim birinci kademe eğitimi olan annelerin çocukları ve hane halkı refah düzeyi düşük veya orta olan çocuklar daha uzun emzirilme sürelerine sahiptirler [9]. Dünya Sağlık Örgütü 2005 verilerine göre genç, evli olmayan, eğitim düzeyi düşük ve aylık geliri düşük olan annelerin emzirme oranları daha düşük saptanmıştır [24]. Ülkemizde yapılan bir araştırmada annenin eğitim düzeyi, yaşı ve ailenin gelirinin çocukların tek başına anne sütü ile beslenme süresini etkilemediği bulunmuştur [25]. Bizim çalışmamızda anne yaşı ve annenin eğitim düzeyi ile tek başına anne sütü ile beslenme süresi ve toplam emzirme süresi arasında ilişki bulunmazken, ailenin aylık geliri arttıkça tek başına anne sütü alım süresinin uzadığı tespit edilmiştir. Hastaların tek başına anne sütü alımı süreleri ile kilo ve boy persantillerinin doğru orantılı olduğu ancak toplam anne sütü alım süresi ve ek gıdaya başlama yaşı ile kilo ve boy persantil değerlerinin değişmediği saptanmıştır.

\section{Sonuç}

Sonuç olarak, çocukluk çağında alt solunum yolu enfeksiyonları en sık hastaneye yatış nedenidir ve hastaneye yatış gerektirecek ağrılıktaki enfeksiyonlar çocukların kilo alımının geri kalmasına neden olur. Ülkemizde ve bizim çalışma grubumuzda erkek ve kadın arasındaki eğitime katılım farklılığı halen devam 
etmektedir. Ailenin aylık geliri tek başına anne sütü ile beslenme süresi üzerine etkilidir. Ebeveyn eğitim seviyesi, ebeveynlerin yaşı ve ailenin aylık ortalama geliri büyüme parametrelerini etkilemeyebilir ancak tek başına anne sütü alım süresi büyüme parametreleri üzerine en etkili faktördür.

\section{Çıkar çatışması / finansal destek beyanı}

Bu yazıdaki hiçbir yazarın herhangi bir çıkar çatışması yoktur. Yazının herhangi bir finansal desteği yoktur.

\section{Kaynaklar}

1. Evliyaoğlu N. Sağlam çocuk izlemi. Türk Pediatri Arşivi 2007; 42:6-10

2. Neyzi $O$, Günöz $H$, Furman A, et.al. Türk çocuklarında vücut ağırığı, boy uzunluğu, baş çevresi ve vücut kitle indeksi referans değerleri. Çocuk Sağlığı ve Hastalıkları Dergisi 2008; 51: 1-14.

3. Oliveira RR, Costa JR. Hospitalization of children under five years of age due to avoidable causes. Rev. Latino-Am. Enfermagem $2012 ; 20: 135-42$

4. Oliveira BR, Viera CS, Furtado MC, et. al. Profile of morbidity of children hospitalized in a public hospital: implications for nursing. Rev Bras Enferm 2012; 65: 586-93.

5. Kösecik M, Cebeci B, Koç A, Tatlı MM. Şanlıurfa'da 5 altı çocukların hastaneye yatırılma ve ölüm nedeleri. Genel Tıp dergisi 1998; 8: 37-40

6. Olack $B$, Burke $H$, Cosmas $L$ et al. Nutritional status of under-five children living in an informal urban settlement in Nairobi, Kenya. J Health Popul Nutr 2011;29: 357-63.

7. Dewey KG, Mayers DR. Early child growth: how do nutrition and infection interact? Matern. Child Nutr 2011; 3:129-42.

8. Kaçar Dilek. Malnütrisyon Tanısı ile 2006-2011 Yılları Arasında Hastanede Yatırılarak Takip ve Tedavi Edilen Beş Yaş Altındaki Hastaların Retrospektif Değerlendirilmesi. Uzmanlık Tezi, ANKARA: 2012.

9. Hacettepe Üniversitesi Nüfus Etütleri Enstitüsü (2009). "2008 Türkiye Nüfus ve Sağlık Araştırması". Hacettepe Üniversitesi Nüfus Etütleri Enstitüsü, Sağlık Bakanlığı Ana Çocuk Sağlığı ve Aile Planlaması Genel Müdürlüğü, Başbakanlık Devlet Planlama Teşkilatı Müsteşarlığı ve TÜBITAK, Ankara, Türkiye.

10. Hacettepe Üniversitesi Nüfus Etütleri Enstitüsü (2014),"2013 Türkiye Nüfus ve Sağlık Araştırması". Hacettepe Üniversitesi Nüfus Etütleri Enstitüsü, T.C. Kalkınma Bakanlığı ve TÜBiTAK, Ankara, Türkiye.

11. T.C Sağlık Bakanlığı,Türkiye Halk Sağlığı Kurumu 2015 Faliyet Raporu: https://www.saglikaktuel.com/d/file/thsk_2015_faaliyet_ raporu.pdf. html 30 Aralık 2018.

12. Türkiye İstatistik Kurumu Verileri 2011. T.C. Türkiye İstatistik Kurumu Başkanlığı 2011, Ankara.
13. Türkiye Aile Yapısı Araştırması 2011. T.C. Aile ve Sosyal Politikalar Bakanlığı Ankara, 2011.

14. Mushtaq MU, Gull S, Khurshid U et.al. Prevalence and sociodemographic correlates of stunting and thinness among Pakistani primary school children. BMC Public Health 2011;11: 790.

15. Jesmin A, Yamamoto SS, Malik AA, Haque MA. Prevalence and determinants of chronic malnutrition among preschool children: a cross-sectional study in Dhaka City, Bangladesh. J Health Popul Nutr 2011; 29: 494-99.

16. Leal VS, Lira PI, Menezes RC et.al. Factors associated with the decline in stunting among children and adolescents in Pernambuco, Northeastern Brazil. Rev Saude Publica 2012; 46: 234-41.

17. Sen P, Bharati S, Som S, Pal M, Bharati P. Growth and nutritional status of preschool children in India: a study of two recent time periods. Food Nutr Bull 2011; 32: 84-93.

18. Kamiya Y. Socioeconomic determinants of nutritional status of children in Lao PDR: effects of household and community factors. J Health Popul Nutr 2011; 29: 339-48.

19. Akova S, Yazar AS, Güven Ş et.al. Anne sütü alan bebeklerin 0-36 ay arası büyüme ve gelişmelerinin değerlendirilmesi. Dicle Tıp Dergisi 2012; 39: 542-46.

20. Pravana NK, Piryani S, Chaurasiya SP et.al. Determinants of severe acute malnutrition among children under 5 years of age in Nepal: a community-based case-control study. BMJ Open 2017; 7: e017084.

21. Muhimbula $\mathrm{H}$, Kinabo J, O'Sullivan A. Determinants of infant nutrition status in rural farming households before and after harvest. Matern Child Nutr. 2019: e12811.

22. Section on Breastfeeding. Breastfeeding and the use of human milk. Pediatrics. 2012; 129: 827- 41.

23. Mihrshahi S, Kabir I, Roy SK et. al. South Asia Infant Feed-ing Research Network. Determinants of infant and young child feeding practices in Bangladesh: secondary data anal-ᄀysis of Demographic and Health Survey 2004. Food Nutr Bull 2010; 31:295-313.

24. Centers for Disease Control and Prevention (CDC). Int. Progress in increasing breastfeeding and reducing racial/ethnic differences - United States, 2000-2008 births. MMWR Morb Mortal Wkly Rep 2013. Available from https://www.cdc.gov/mmwr/preview/ mmwrhtml/mm6205a1.htm.

25. Gün I, Yılmaz M, Şahin H et. al. Kayseri Melikgazi Eğitim ve Araştırma Bölgesi'nde 0-36 aylık çocuklarda anne sütü alma durumu. Çocuk Sağlığı ve Hastalıkları Dergisi 2009; 52: 176-82. 